\title{
Employee Online Surveys: Satisfaction, Engagement, Loyalty, and Readiness for Personal Branding
}

\author{
Leyla H. Alikhanova ${ }^{1}$ Oksana K. Mineva ${ }^{2}$ Diana Sh. Smirnova ${ }^{2, *}$
}

\author{
${ }^{1}$ School of Economics Azerbaijan State University of Economics, Baku AZ 1001, Azerbaijan \\ ${ }^{2}$ School of Management, Astrakhan State University, Astrakhan 414056, Russia \\ *Corresponding author. Email: dsmirnovad@mail.ru
}

\begin{abstract}
Employee engagement is understood by us as the highest stage of commitment. In our understanding, this is such a physical, emotional and intellectual state that can motivate employees to perform their work as efficiently as possible. Achieving employee engagement is a guarantee of the efficient operation of the company and its long-term competitiveness. In order to analyze the individual components of an employee's commitment to the company in recent years, online survey systems have become popular around the world. We identified eight key areas of employee surveys. We conducted a comparative substantive analysis of five software products based on online surveys of employees and revealed one common drawback. This disadvantage lies in the fact that little attention is paid to such a stage in the life cycle of an employee in an organization as readiness for a career and personal branding. We proposed a direction and tools for such an analysis with testing the effectiveness of the stage for 340 employees. You can be sure that the study of readiness for personal branding provides an opportunity to identify and evaluate the career potential of an employee and increase his level of loyalty in the long term to the highest commitment to the company.
\end{abstract}

Keywords: online surveys, stage of commitment, employee branding, stage of loyalty, employee engagement,

employee satisfaction

\section{INTRODUCTION}

To manage employee performance, data collection is required in various forms and at various points in the employee's life cycle. Historically, industrial companies were the first to conduct employee surveys in 1920-1944. In the context of competition for highly productive personnel, companies were looking for ways to attract and retain it. The National Industrial Advisory Council saw productivity growth of more than $200 \%$ in those companies that conducted surveys and adjusted their work with personnel. An increase in interest in this issue occurred during the Second World War. It was necessary to measure the attitude of the military, soldiers and officers towards the leadership of the army.

Currently, more than $60 \%$ of enterprises worldwide conduct employee surveys on a regular basis. The key task is to evaluate at various points in the employee's life cycle his involvement, workplace culture, profitability of human capital and commitment. In the United States, such surveys are regularly conducted by all United States federal agencies [1]. The results of these surveys are available at www.opm.gov. Labor market experts focus on the relationship between employee engagement and employee performance [2]. The Russian company ECOPSI (www.ecopsy.ru), according to a study of a large industrial holding, established $82 \%$ correlation between the engagement index and labor productivity. It is important to highlight that high staff satisfaction does not guarantee organizational performance. Happy Job research (www. Happy-job.ru), which was attended by 574,000 respondents, revealed a low correlation between job satisfaction and productivity. The company's studies show that the overall satisfaction of workers in Russia is $65.6 \%$ in 2018-2019. At the same time, young specialists up to 25 years of age receive the least satisfaction from work. In our opinion, this is due to the lack of interest of the employer in long-term work with the employee. Studies conducted by a number of the foreign companies show what are the positive differences between a company with a high level of staff commitment.

1) Higher value of company shares (on average for $12 \%$ ).

2) More sales per employee (the difference is up to $\$$ 27,000).

3) Higher profit margins (on average for $5 \%$ ).

4) The value of the index of customer satisfaction is higher (5-10\% more).

For the analysis of separate components of commitment of the employee in relation to the company in recent years, online survey systems have become popular around the world. 


\subsection{Related Work}

According to the type of understanding of commitment, we divided the existing work in this area into three categories.

\subsubsection{Pyramid of commitment}

In the first sense, staff involvement is the level of adaptation of a new person to the role of an organization employee. William Kahn provided the first formal definition of employee involvement as an affection for members of an organization in their work roles. His research revealed that the people involved use and express themselves more actively physically, cognitively and emotionally during the implementation of role-playing behaviour [3]. Figure 1 shows several levels of employee commitment to the company.

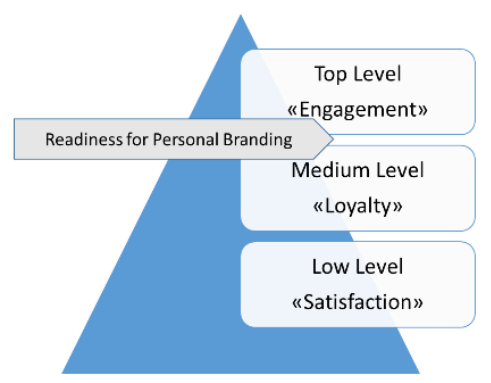

Figure 1 Pyramid of commitment

At the level of "Satisfaction" - the employee as a whole is satisfied with the company in which he works. He is pleased with certain components, for example, salary, working conditions, training opportunities. The employee will continue to work, but will not make much effort. Loyalty means that the employee likes the company. The employee is ready to work in the organization for a long time, he is loyal to the company. However, the employee does not work hard [4].

The Engagement level is considered the highest level of commitment. The employee lives in the interests of the company [5]. He gives his best and tries to work as best as possible. This can be compared to entrepreneurship. The employee perceives the business of the company as his own. The employee considers it his duty to do everything possible for the company.

\subsubsection{Initially, satisfaction, and only then start the movement through the stages of commitment}

An employee's commitment can arise only if he is initially satisfied with the work. In this approach, employee engagement is an approach to business management based on taking into account the influence of an organization's employee on its personal policy (personal branding), organization development policy and enterprise performance [6].
This is an approach presented by the Gallup Institute. The standardized Q12 questionnaire from Gallup is used. In studies conducted by Gallup, an indicator of employee participation in the engagement process is the de facto level of job satisfaction [7]. Speaking more simply involved in the work can only be one who is satisfied with this work. This makes job satisfaction and engagement work complementary concepts. The approach deserves attention mainly because it embeds involvement in work in a more specialized practical model [8].

\subsubsection{Commitment is equal to involvement and degree of labor participation}

This is the JobDemand-Resource theory [9]. Involvement in turn is understood as a positive state of mind of an employee, which is characterized by a contribution to work (workengagement), energy, concern and dedication to work.

Vigor (Vigor) refers to the experience during work, a feeling of energy and immunity to fatigue, mental and physical.

Dedication refers to the belief that what matters is the work and its fulfillment is important and can be proud of.

Work preoccupation (Absorbtion) refers to the experience during the work of full concentration on the tasks performed, which may be accompanied by a sense of rapid passage of time [10].

In this theory, engagement is clearly distinguished from job satisfaction. Job satisfaction is seen as an employee's state of consciousness [11]. Cognitive assessment of satisfaction, the process of perception and interpretation by the subject of certain labor circumstances. Job satisfaction is a subjective picture of the situation in the human mind [12]. Engagement is an objective assessment of employee performance.

The approach deserves attention mainly because it embeds involvement in work in a more specialized theoretical model.

According to the methodology, employee engagement is a measurable level of positive or negative attachment to work, colleagues and the organization that affects learning and excellence in work.

\subsection{Our Contribution}

Standard questionnaires show increased involvement and do not reveal the true problems with the staff.

Online personal branding readiness assessment is our innovative development. It is based on the classification of needs and motivating factors that determine the employee's commitment to the company. You can be sure that during the study of readiness for personal branding, we will 
identify the career potential of the employee and increase the level of his loyalty in the long term.

\section{PROBLEM STATEMENT}

Consider the methods and tools for determining readiness for personal branding.

We invest in the brand of the organization and increase the value of the employees of the organization, getting an integrated synergistic effect. It should be reflected in the positive dynamics of rating assessments of the subsystems of the organization's personnel management strategy and the aggregate index of personnel satisfaction with working conditions and labor relations. Ideally, we are proud of the people who "Choose" our organization, and employees are proud that the organization "Choose" and entrusted them with the opportunity to work.

In the branding of personnel, it is necessary to lay the priority of talented employees at the stage of searching for candidates and test selection of personnel. For this, evaluating the effectiveness of talented personnel management, three approaches can be distinguished.

\subsection{Traditional Method}

The first approach is the traditional approach. This approach evaluates the effectiveness of talented personnel management based on the final results of production, that is, the company's profit, profitability by type of activity, dividends on the company's shares, capital productivity ratio and so on [13]. It involves the recruitment of personnel that is capable of showing high labor discipline, demonstrates high theoretical and practical knowledge at the stage of preliminary testing.

The traditional approach is based on the postulates that "Workers need an organization because there is a shortage of good jobs in the market" and the main competitive advantage is "Equipment, location and access to resources". People chosen by the company are perceived by senior management as "lucky" who will be satisfied with the very fact of a job guarantee and the basic social and compensation package. With this approach, only medium to medium ones can be selected. In this option, any talented employee with a potential above the average level will be perceived by the team as a threat. Moreover, the leadership will be the most nervous about the talented employee, perceiving it as a threat to their "position". The contrast of talent against the background of the gray team is almost always the exclusion of talent from the team. To substitute a talented employee and show the "newcomer" his "place" is, unfortunately, a postulate of the traditional system. We can recall two expressions characterizing the traditional approach "There are no replaceable people" and "There is no person, there is no problem". The procedures and branding methods of an individual employee or group become not only unnecessary, they can even be recognized as "harmful" by the traditional system.

\subsection{Effective Method}

The second approach is an effective approach. According to the second approach, the main indicator of personnel management efficiency is the dynamics of labor productivity coefficient and the ratio of labor productivity growth rates to wage growth rates. It involves the recruitment of personnel who are able to show higher in comparison with the average market productivity, knowledge of new working methods, familiarity with the latest tools and technologies. This approach is most effective for companies if their products are knowledgeintensive and time-consuming.

Make a decision on hiring personnel; in this approach, the ratio of price and quality is always considered before. The employer analyses how much the employee costs and what he can give the organization [14]. Talented employees are a symbol of success for any company. For market leaders such as Google, Intel, Jonson \& Jonson, General Electric, this is an obvious strategic priority for companies. A comparative analysis conducted by McKinsey in the period 1998-2008 clearly demonstrated that the difference between mid-level companies and market leaders is precisely the strategic priority of talented personnel [15]. Strict selection criteria allow you to hire only the best of the best [16]. The slogan of this approach is "The organization needs talented employees", and the higher the talent of the employee, the more he is in short supply and, as a result, more expensive in the labor market. The market is represented by short-term contracts and an active hunt for the best.

\subsection{Long-term Method}

The third approach is long-term commitment. This method takes into account staff loyalty and focuses primarily on the level of motivation. In this approach, priority is given to the dynamics and analysis of the reasons for staff turnover in certain categories of employees, as well as the cost of training and their effectiveness. Employees with high growth and development potential are selected. Priority is given to those who have already achieved recognition in their professional industry and (or) in related industries. Separately, the costs of intangible methods of stimulating talented employees are considered. The more the employee is branded, the more prestigious the fact of his work with us. Imagine that you are not buying employees, but batteries. You buy two batteries of different brands for the same price and expect that it will work for a week without recharging. You paid the same price for batteries of different companies, but if one of them is the "right" talented battery, then it will work much better than another, ordinary battery. As a result, recharging a regular battery, i.e. By paying regular salaries to employees, you get industry average productivity. While the right battery makes for the same paycheck it works many times more. Having bought such a magic battery once, if you want to buy something else, we are sure not. Just like a hare of a "different color" from an Energizer battery advertisement, 
a talented employee is a clear guarantee of the declared quality. But even the most talented employee cannot work month after month without recharging. Yes, its potential is higher than usual, but it will cost, the farther, the more expensive, both at the time of recharging, and during maintenance.

In the case of an employee with a high potential for engagement, the situation will be even better. You will not only be able to wait for a greater charge to work in a long period, you also have a huge potential for increasing the charge. This means literally the following, a dedicated, dedicated branded employee will be able to charge much more devices per unit of time, his capacity is unlimited, his labor productivity is growing, he can become tens of times higher than the efficiency of an ordinary employee. The most profitable thing in the story with the employee involved at the highest level of commitment is that at the first stage of the purchase it can cost no more than an ordinary employee. In some cases, it can even be cheaper. Willingness to responsibly and efficiently perform interesting work at this stage of his career, for a smaller amount of money is one of the key differences of high potential. The main thing is to consider its potential and start investing in the right person. Only using the publicity system of the employee's achievements and the evidence of his exclusivity, we get a personal brand. The system for assessing the readiness for personal branding and the personal branding of personnel itself becomes not only necessary for the organization, it becomes a priority and gives "maximum usefulness".

Employees with high potential for engagement want to learn. Employees understand that the knowledge and skills acquired during the training process, help in the performance of official duties, are the key to career development and growth and provide psychological satisfaction from work. In general, with the proper organization of training, the effectiveness of activities increases and labor motivation increases and the level of commitment of the company increases.

\section{MATERIALS AND METHODS}

We identified eight key areas of employee surveys.

1. Acceptance of corporate culture and values by employees - how much employees agree with corporate values and whether they accept organizational culture.

2. Relations with colleagues - the comfort of the psychological climate that has developed in the team.

3. Relations with company management - how accessible and open the company management is.

4. Employee satisfaction with the characteristics of the work performed [17].

5. The justice of remuneration for work is openness and the structure of remuneration is clear, what needs to be done to receive compensation, benefits, bonuses and payments.
6. Opportunities for training and development - how useful and effective the employees consider the corporate training system.

7. Career potential and employee readiness for personal branding - how much employees need career growth and personal recognition.

8. Employee involvement in changes (changes in the organization) and innovations - how positively do employees perceive changes in the company and how they are ready to participate in the implementation of innovations.

The study of the effectiveness of the online programs in the eight areas listed above are presented in the table. Expert assessment was carried out on a 10-point scale, where the 0 -direction of the assessment is absent, 10 - the direction of assessment is presented in full. The survey was conducted by 15 labor market experts and a weighted average was calculated for each area.

Table 1 Online programs

\begin{tabular}{|l|l|l|l|l|l|l|l|l|}
\hline $\begin{array}{l}\text { SmartSatisfaction } \\
\text { Monitoring }\end{array}$ & 5 & 7 & 6 & 7 & 4 & 6 & 2 & 6 \\
\hline Simonitor & 5 & 6 & 5 & 7 & 7 & 7 & 1 & 4 \\
\hline Happy Job & 8 & 7 & 7 & 6 & 8 & 5 & 0 & 8 \\
\hline $\begin{array}{l}\text { SAP } \\
\text { SuccessFactors }\end{array}$ & 7 & 8 & 9 & 7 & 8 & 7 & 3 & 6 \\
\hline Qualtrics & 9 & 10 & 8 & 9 & 10 & 10 & 4 & 10 \\
\hline
\end{tabular}

As follows from the data in Table 1, qualtrics is the undisputed leader. Worst of all, popular polls currently reflect career potential and employee readiness for personal branding. The questionnaires of a number of Russian companies received lower ratings compared to their foreign counterparts.

As our study showed, an online satisfaction survey, and determining the level of commitment, is a complete multivariate study.

The directions of our research on online questionnaires are presented in table 2.

Due to the on-line questionnaire, you can customize the profiles according to your specifics. You can consider the interests of the company in the questionnaire. Ample opportunities for analysis and comparison of results. If necessary, you can use various analytics tools. Compare reports of different departments, branches and for different periods of time. According to the results of an online survey, you can combine several reports into one. You can also receive data by personnel categories, duration of work and other criteria.

If not all employees had access to a computer, smartphone and / or Internet access, then an alternative was to interview on printed forms. We printed the forms, the employees filled them in, then the forms were scanned and loaded into the system. Processing of completed questionnaires occurred automatically. It was very simple and fast.

It should be noted the high functionality of the service regardless of the size of the company. Online employee assessment is suitable for both small businesses and large corporations with an extensive branch network. All data of 
users of online surveys is easy to protect and encrypt, ensuring the anonymity of the responses of survey participants. This means that management received more complete and sincere responses from employees, and the survey results were reliable.

Table 2 Online survey used in our study

\begin{tabular}{|c|c|}
\hline Areas of analysis & Estimated characteristics \\
\hline $\begin{array}{l}\text { Employee Satisfaction } \\
\text { Analysis }\end{array}$ & $\begin{array}{l}\text { Working conditions } \\
\text { Workplace comfort } \\
\text { Labor content } \\
\text { Salary } \\
\text { Security }\end{array}$ \\
\hline $\begin{array}{l}\text { Employee Loyalty } \\
\text { Analysis }\end{array}$ & $\begin{array}{ll}\text { Readiness } & \text { for } \\
\text { recommendation } & \\
\text { Short-term willingness to } \\
\text { change jobs } \\
\begin{array}{l}\text { Long-term willingness to } \\
\text { change jobs }\end{array} \\
\begin{array}{l}\text { Desire for development } \\
\text { Pride }\end{array} \\
\end{array}$ \\
\hline $\begin{array}{l}\text { Analysis of employee } \\
\text { readiness for personal } \\
\text { branding }\end{array}$ & $\begin{array}{l}\text { Personal PR } \\
\text { Knowledge of training info } \\
\text { layouts } \\
\text { Priorities for Employee } \\
\text { Personal Branding Tools } \\
\text { Ratings to motivate the size } \\
\text { of a personal branding } \\
\text { budget }\end{array}$ \\
\hline $\begin{array}{l}\text { Employee Engagement } \\
\text { Analysis }\end{array}$ & $\begin{array}{l}\text { Trust } \\
\text { Leadership } \\
\text { Productivity } \\
\text { Tolerance }\end{array}$ \\
\hline
\end{tabular}

\section{THE RESULTS DISCUSSION}

The issue of personal branding is largely a matter of budget. How much are you willing to spend on the brand of your staff, taking into account the long-term effect. If you adhere to such an indicator as the lifetime value of personnel, then you need to focus on the average expected life of the staff in the organization. We represent this indicator in the form of a formula. We proposed a direction and tools for such an analysis with testing the effectiveness of the stage for 340 employees.

The costs of branding personnel should be lower than the expected discounted amount of positive cash flow of profit from personnel.

However, for the effectiveness of personal branding of such employees, it is necessary:

- exercise constant control over bottlenecks and, as a result, quick response to difficulties arising in the organization;

- develop a mechanism for assessing the quality of employee training and adequate remuneration.

In the framework of solving these problems, the following activities can be proposed:
1) the creation of a training portal on the organization's website to realize the possibilities of distance learning for employees and their passage through all stages of commitment;

2) the use of assessment-center methodology to evaluate employees, determine the appropriateness and areas of training;

3) creating a feedback system for compiling a list of desired "rewards" for employees who have shown the best results during training;

4) on-line monitoring of employees using a survey system. The proposed system is presented in Figure 2.

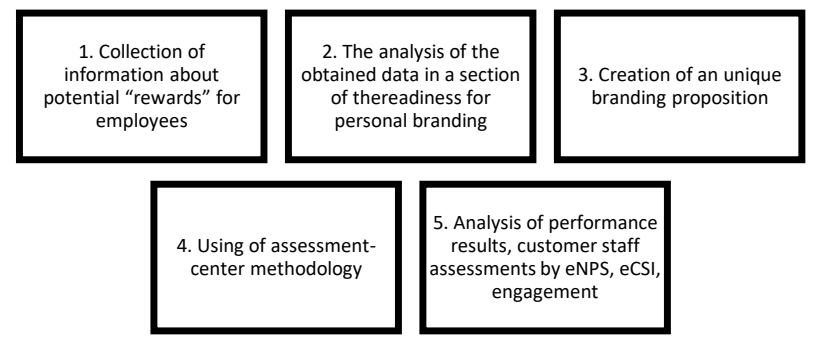

Figure 2 Employee personal branding system

The activities proposed in the article will increase the involvement of employees forming the highest level of commitment.

In our studies, we considered involvement as a method of diagnosing employee attitudes towards our work in particular and to the company as a whole, this is closest to the first version of the concept of engagement.

Using eight areas of the survey, we determined how to improve the system for assessing employee commitment. The level of staff involvement can be used to assess the quality of the company's HR service. The higher the value, the better the HR department of the company works.

Our research shows that engagement has a strong correlation with business results (from $75 \%$ to $81 \%$ ). The transition from loyalty to engagement has confirmed productivity growth (an average of 10\%). Career opportunities and (or) access to personal branding tools reduce staff turnover. We observed a decrease in staff turnover on average, by the group of middle administrative level, by $18 \%$.

A high level of involvement provides, against the background of an increase in employee productivity, a simultaneous increase in customer satisfaction and loyalty. This is, in our opinion, the most important factor.

In general, the use of online methods of interviewing personnel has reduced the cost of recruiting and adapting personnel and improving the company's image and reputation in the market.

An increase in the level of involvement by $1 \%$ in the range of 70-80 ensures an increase in employee productivity by $4 \%$, an increase in customer satisfaction of an enterprise by 
and Governance, 2015, vol. 19(2), pp 371-394. DOI https://doi.org/10.1007/s10997-013-9264-7

Improve professional competencies of employees we increase their value in the labor market.

\section{CONCLUSION}

The best tool for evaluating the effectiveness of the organization's personnel management is online surveys. The transition to on-line employee assessment technologies provides the following benefits.

1. Simplicity and convenience in the work of individual departments of the company and the HR service of the company as a whole.

2. High speed of analysis and report. Survey can be done in one day.

3. The ability to monitor the progress of research employees online.

4. You can get detailed and reliable results of engagement for each individual employee.

5. Ample opportunities for analysis and comparison of results both for one employee and for categories of personnel and departments for different periods of time.

6. You can conduct surveys in any format and for organizations with any number of employees.

7. Accessibility and simplicity of conducting rapid surveys of staff commitment, monitoring system - "Employee Pulse" (survey on indicators).

In our studies, using eight areas of the survey, we determined how to improve the system for assessing employee commitment. Our research shows that engagement has a strong correlation with business results (from $75 \%$ to $81 \%$ ). The transition from loyalty to engagement has confirmed productivity growth (an average of 10\%). Career opportunities and (or) access to personal branding tools reduce staff turnover. We observed a decrease in staff turnover on average, by the group of middle administrative level, by $18 \%$.

A high level of involvement provides, against the background of an increase in employee productivity, a simultaneous increase in customer satisfaction and loyalty. An increase in the level of involvement by $1 \%$ in the range of 70-80 ensures an increase in employee productivity by $4 \%$, an increase in customer satisfaction of an enterprise by $8 \%$ (CSAT), and an increase in loyalty by $2 \%$ (NPS).

The use of personal branding tools for a specific employee is a guarantee of their high loyalty and motivation.

\section{REFERENCES}

[1] Proposed Standards and Guidelines for Statistical Surveys, 2018 https://www.whitehouse.gov/wpcontent/uploads/2018/05/statistical-programs-2018.pdf

[2] F. Gangi, C. Trotta, The ethical finance as a response to the financial crises: An empirical survey of European SRFs performance, Journal of Management
[3] A. Kahn, William, Psychological Conditions of Personal Engagement and Disengagement at Work, Academy of Management, 1990, vol. 33, № 4, pp 692724. ISSN / 25628710.2307 / 256287

[4] K. Ogunyemi, Employer Loyalty - The Need for Reciprocity, Philosophy of Management, 2015, vol.13. DOI: https://doi.org /10.5840 / pom201413315

[5] M. Gupta, S. Mikkilineni, Spirituality and Employee Engagement at Work, The Palgrave Handbook of Workplace Spirituality and Fulfillment, 2018, pp 1-17. DOI: https://doi.org/ 10.1007/978-3-319-62163-0_20

[6] D.A. Dillman, J.D. Smyth, L.M. Christian, Internet, Phone, Mail, and Mixed-Mode Surveys, Publisher: Wiley, 2014, 4 edition, p 528. ISBN-10: 1118456149 , ISBN-13: 978-1118456149

[7] L.N.Spiro, Media; Gallup, the Pollster, Wants to Be Known for Its Consulting, The New York Times, 2003

[8] P. M. Podsakoff, S. B. MacKenzie, J. Y. Lee, N. P. Podsakoff, Common method biases in behavioral research: A critical review of the literature and recommended remedies, Journal of Applied Psychology, 2003, 88(5), 879

[9] E. Demerouti, Job Demands-Resources Theory. Wellbeing: A Complete Reference Guide, 2014, vol. 3, pp 37-64. DOI: https://doi.org/10.1002/9781118539415 .wbwell019

[10] W. Schaufeli, M. Salanova, V. Gonzalez-Roma, The Measurement of Engagement and Burnout: A Two Sample Confirmatory Factor Analytic Approach, Journal of Happiness Studies, 2002, vol. 3. pp 71-92. DOI: https://doi.org/ 10.1023/A:1015630930326

[11] P. Bockerman, P. Ilmakunnas, The Job SatisfactionProductivity Nexus: A Study Using Matched Survey and Register Data, ILR Review, vol. 65, no. 2, pp 244-262

[12] S. Einarsen, A. Skogstad, E. Rørvik, A. Lande, M. Nielsen, Climate for conflict management, exposure to workplace bullying and work engagement: a moderated mediation analysis, The International Journal of Human Resource Management, 2016, pp. 1-22. DOI: https://doi.org/ 10.1080/09585192.2016.1164216

[13] M. Farrukh, R. Kalimuthuan, S. Farrukh, Impact of Job Satisfaction and Mutual Truston Employee Loyalty in Saudi Hospitality Industry: A Mediating Analysis of 
[16] E.G. Chambers, M. Foulon, H. Handfield-Jones, S.

Leader Support, International Journal of Business and Psychology, 1(2), 2019, pp 30-52

[14] F.Tentama, S.Subardjo, S. Mulasari, M. Eka, The Role of Job Satisfaction on Employee Work Productivity,2019, 4. DOI: https://doi.org/ 10.2991/iconprocs-19.2019.25

[15] McKinsey's Value of Better Talent Research), 2000, 2008
Hankin, E. Michaels, The War for Talent, The McKinsey Quarterly1998, 3, pp 44-57

[17] P.R. Knapp, G. M. Bahaudin, Designing, administering, and utilizing an employee attitude survey,Journal of Behavioral Studies in Business, 2010, vol. 2 https://docplayer.net/10437235-Designingadministering-and-utilizing-an-employee-attitudesurvey.html 